\title{
fTELLÊ \\ Algunas notas sobre el proceso organizativo de la gente negra en el Pacífico Sur colombiano
}

\author{
Algumas notas sobre o processo organizativo dos \\ afrodescendentes do Pacifico Sul colombiano \\ Quelques notes sur le processus d'organisation de la \\ population noire du Pacifiaue Sud colombien
}

\author{
Tulio Andrés Clavijo Gallego \\ Universidad del Cauca, Colômbia \\ taclavijo@unicauca.edu.co
}

\begin{abstract}
Resumen
A partir de la promulgación de la Constitución Política colombiana de 1991 y del posterior desarrollo de la Ley 70 de 1993, mejor conocida como 'ley de las negritudes', se consolidaría un escenario concreto de reconocimientos étnicoterritoriales para las 'comunidades negras' que venían habitando las tierras bajas del Pacífico colombiano. A pesar de que buena parte de estos logros estuvieron antecedidos por un arduo proceso organizativo de la gente negra del Pacífico y del norte del departamento del Cauca, la producción académica ha centrado mayoritariamente su atención en lo acontecido en departamentos como Choco, Valle del Cauca y Nariño, generando consciente o inconscientemente un imaginario sesgado que revela algunos elementos con mayor contundencia a la vez que oculta otros, restándoles visibilidad. El presente artículo intenta presentar algunas piezas de la historia no contada en procura de aportar al balance de la ecuación, ilustrando algunos momentos de lo acaecido con el proceso organizativo de la gente negra en el Pacífico caucano durante las últimas tres décadas, -con espacial referencia en el municipio de Guapi -, a la vez que esboza una suerte de balance sobre lo que ha significado la concreción de la Ley 70 en el Pacífico caucano a más de 20 años de haber entrado en vigencia.
\end{abstract}

Palabras clave: Territorio, Ley 70 de 1993, Pacífico sur, Guapi, comunidades negras.

\section{Resumo}

A partir da promulgação da Constituição política colombiana de 1991 e do posterior desenvolvimento da Lei 70 de 1993, conhecida como a "lei da negritude", consolidase um cenário específico de reconhecimento étnico-territorial para as "comunidades negras' que vinham habitando as terras baixas do Pacífico colombiano. Apesar de que boa parte das conquistas estiveram antecedidas por um difícil processo organizativo 
das pessoas negras do Pacifico e Norte do departamento de Cauca, a produção acadêmica tem centrado principalmente sua atenção no acontecido em departamentos como Chocó, Valle do Cauca e Nariño, gerando consciente ou inconscientemente, um imaginário distorcido que revela alguns elementos com maior contundência e, por sua vez, oculta outros, restando-lhes visibilidade. Este artigo tenta apresentar algumas peças da história não contada, na tentativa de contribuir com o balanço da equação, ilustrando alguns momentos do acontecido com o processo de organização da população negra no Pacífico caucano durante as últimas três décadas, com referência ao município de Guapi - a sua vez que esboça espécie de balanço sobre o que há significado a concreção da Lei 70 no Pacifico caucano a mais de 20 anos, desde que entrou em vigência.

Palavras-chave: Território, Lei 70 de 1993, Pacífico Sul, Guapi, comunidades negras.

\begin{abstract}
Résumé
Dès la promulgation de la Constitution Politique colombienne de 1991 et plus tard de la Loi 70 de 1993, plus connue comme la "Loi des negritudes", s'est développé puis consolidé tout un mouvement pour la reconnaissance ethnico-territoriale des "communautés noires" qui venaient habiter les basses terres du Pacifique colombien. En dépit du fait qu'une bonne partie de ces avancées aient été précédées par un laborieux processus d'organisation des communautés noires du Pacifique et du Nord du département du Cauca, la production académique a majoritairement concentré son attention sur ce qu'il s'est produit dans les départements comme le Choco, la Valle del Cauca et Nariño. Ceci a alors généré consciemment ou inconsciemment un imaginaire biaisé qui révèle certains éléments avec plus insistance que d'autres, ces derniers alors occultés ou privés d'une meilleure visibilité. Le présent article tente de présenter quelques pièces de l'histoire non contée dans le but de les apporter à l'équilibre de l'équation, illustrant certains éléments survenus au sein du processus d'organisation de la population noire du Pacifique du Cauca durant les trois dernières décennies - avec une référence particulière au municipio de Guapi. Ce qui dans une autre mesure permet de faire une sorte de bilan de ce qu'a signifié la promulgation de la Loi 70 dans la région du Pacifique du Cauca plus de 20 ans après être entrée en vigueur.
\end{abstract}

Mots-clés: Territoire, Loi 70 de 1993, Pacifique sud, Guapi, communautés noires.

[...] donde hay poder hay resistencia, y no obstante (precisamente por esto), ésta nunca está en posición de exterioridad respecto del poder. (Foucault [2011] 1973: 89).

\title{
A manera de introducción
}

Si bien la década de los años noventa del siglo anterior mostró como nunca antes la confluencia de múltiples dinámicas en torno al proceso de movilización y organización de la gente negra en Colombia con un claro anclaje en las tierras bajas del Pacífico, es también cierto que dicha emergencia es comprensible -en un sentido profundo- sólo si se vincula a ella un análisis retrospectivo de mayor aliento. Ahora bien, sin desconocer eventos anteriores, el último cuarto del siglo XX puede articularse como un punto de análisis fructífero para examinar la trayectoria del proceso organizativo en cuanto a los discursos y prácticas que se profirieron, por un lado, desde 
los ámbitos académico/urbanos -con un claro referente en los procesos antisegregacionistas vivido en los Estados Unidos- y de otro, por la fuerte presencia en la región del Pacífico de vertientes misioneras de la iglesia católica, quienes abanderaron en su quehacer el fortalecimiento de grupos de base con una fuerte "[...] sensibilidad al discurso etnicista". (RESTREPO, 2005, p. 144). ${ }^{1}$

En línea directa fueron variados en enfoque, fuente y alcance los registros que desde el ámbito académico e investigativo, así como de las organizaciones sociales se realizaron. ${ }^{2}$ Sin embargo, después de una lectura un poco más detallada es posible advertir cómo existe un cierto desbalance en esta producción si se compara por ejemplo la costa Pacífica caucana con el resto de los departamentos del Litoral, predominando así las lecturas realizadas para y desde el Pacífico chocoano, vallecaucano y nariñense. Es justamente ese 'desbalance' el que justifica en parte el presente texto, en el afán sincero de mostrar otras lecturas y dinámicas ancladas en el Pacífico sur que quizá no alcanzaron a tener el grado de difusión de otros procesos, pero que sin lugar a dudas no sólo caminaron en muchas momentos de manera paralela a los lineamientos más visibles de la movilización, sino que desde diferentes lugares articularon y se sumaron al proyecto de pensar el Pacífico desde otras lógicas. Así, en el intento de aportar algunos elementos para la reflexión, propongo tres momentos en mi argumentación, aunando a ellos un espacio final de conclusiones provisionales. En una primera parte presentaré una breve síntesis sobre la historia del proceso organizativo de la gente negra en el Pacífico en un contexto general, esto tratando de no caer en la reiteración sin sentido, pues es un tema ampliamente documentado. Sobre todo, me interesa mostrar algunas particularidades acaecidas en el Pacífico surcolombiano, específicamente en el departamento del Cauca. En un segundo momento, me detendré en el análisis de tres organizaciones sociales existentes en el municipio de Guapi, por las cuales tengo especial afecto, no sólo por la amistad que me une con muchos de sus miembros y activistas, sino por haber desarrollado algunas tareas conjuntas tanto en el Plan Ambiental de Comunidades Negras ${ }^{3}$ (ASOPOMY, 2007) como en mi trabajo de campo para esta investigación. Posteriormente trataré de esbozar un balance de los logros y pendientes de la Ley 70 de 1993, teniendo como punto de referencia nuevamente al municipio de Guapi. Finalmente, formularé algunas conclusiones provisionales sobre lo enunciado. Espero poder cumplir -al menos parcialmente- con lo insinuado.

\footnotetext{
${ }^{1}$ Según Eduardo Restrepo, que la gente negra en Colombia sea representada como un grupo étnico, deviene de una dinámica de 'etnización', por la cual entiende “[...] el proceso mediante el cual una o varias poblaciones son imaginadas como una comunidad étnica. Este continuo y conflictivo proceso incluye la configuración de un campo discursivo y de visibilidades desde el cual se constituye el sujeto de la etnicidad. (RESTREPO, 2005, p. 143).

${ }^{2}$ Para tener algunos referentes sobre el proceso organizativo del Pacífico ver entre otros: RESTREPO (2004), (2005); HOFFMAN (2007), CASTILLO (2007) y OSLENDER (2008).

${ }^{3}$ La formulación del Plan Ambiental de Comunidades Negras para la costa Pacífica caucana se realizó entre los años 2004 y 2007, financiado por la Corporación Autónoma Regional del Cauca (CRC) y ejecutado por la Asociación de Organizaciones Populares del Micay (ASOPOMY). En este proceso tuve la oportunidad hacer parte del equipo técnico como geógrafo, lo que a su vez representó primera experiencia de trabajo en el Pacífico sur.
} 


\section{Sobre el proceso de movilización y organización del Pacífico colombiano}

Desde mediados de la década de los años setenta se empezaría conformar un anclaje discursivo que para el caso de la gente negra en Colombia encontraría dos visiones de proceso, una, manifiesta en el movimiento Cimarrón, integrado básicamente por profesionales y universitarios, fortalecidos con sus círculos de estudios y sus referentes enmarcados en la lucha contra el racismo en Estados Unidos y en Suráfrica, la otra, encarnada por las organizaciones étnico-territoriales localizada en la parte rural, que se hizo más notoria y específica en el departamento del Chocó, esto bajo la orientación y el amparo de la rama eclesial. Para la década de los años ochenta, y con el apoyo de la Pastoral Afroamericana de la Iglesia Católica nace la Asociación Campesina Integral del Río Atrato (ACIA). ${ }^{4}$

Esta noción y estrategia organizativa respondía a la creciente amenaza de despojo de las tierras habitadas por estas poblaciones durante varias generaciones, a manos de un Estado que desconocía su presencia. Este desconocimiento se daba mediante la declaración de gran parte de la región del pacífico como 'zonas baldías' (estos es, pertenecientes a la 'nación') y, por lo tanto eran otorgadas concesiones o permisos de explotación de sus recursos forestales y mineros a compañías foráneas. (RESTREPO, 2004, p. 272).

Ahora bien, este tipo de emergencias - como se sabrá- no son exclusivas del Pacífico colombiano ${ }^{5}$, tienen infinitas manifestaciones en cada rincón del planeta y su historia ha estado siempre bajo la rúbrica de la 'resistencia', , a lo que WALLERSTEIN (2008) ha denominado la economía mundo capitalista.

\footnotetext{
4 "La ACIA constituye sin duda la primera organización en Colombia (y quizás en América) que define la comunidad negra como un grupo étnico, esto es, en términos del derecho a la diferencia cultural de una comunidad definida desde su ancestralidad y alteridad". (RESTREPO, 2004, p. 272). Aquí es importante señalar por ejemplo, que "para 1997, la Acia había logrado una meta increíble en su negociación con el gobierno: la demarcación de 600.000 hectáreas que, aunque todavía no habían sido legalmente tituladas a la organización, fueron colocadas bajo un plan de manejo especial basado en las prácticas culturales de las comunidades" (ESCOBAR, 2010, p. 67). Sin lugar a dudas, este evento marcó un precedente referido a nuevos órdenes territoriales en el Pacífico, sin embargo, sólo una década después la ACIA recibiría el título legal.

5 “[...] la reivindicación del carácter espiritual-religioso del modo de vida y del pensamiento indígena -o de los grupos de ascendencia africana o, en general, de los grupos locales en muchas partes del globo- se ha convertido en los últimos años en un eje estratégico de reclamaciones identitarias". (SERJE [2005] 2011, p. 250).

${ }^{6}$ Según Restrepo, 'resistencia', “[...] es uno de los conceptos más recurrentes en la teoría política, pero uno de los menos elaborados. [...] el concepto de resistencia amerita ser cuidadosamente utilizado. Antes que un punto de partida es un punto de llegada. Para considerar una práctica, representación o relación como resistencia, se requiere demostrar bajo qué contexto concreto de relaciones de poder opera como tal. Además de su singularidad, al recurrir a este concepto se debe examinar la densidad, los contrastes y las multiplicidades que constituye una acción (u omisión) como resistencia. Más que resistencia y dominación como bloques monolíticos definidos de antemano, lo que merece ser explorado son resistencias y dominaciones en la pluralidad de sus entramados y la multiacentualidad de sus significados". (RESTREPO, 2008, p. 41-42).
} 


\begin{abstract}
Desde sus primeros años, la economía-mundo capitalista, que funciona desde por lo menos hace cinco siglos, ha provocado siempre fuertes resistencias por parte de los trabajadores, y ello bajo formas diversas: revueltas campesinas, motines de hambre, movimientos mesiánicos, e incluso diversas formas de vandalismo social. Pero es hacia el siglo XIX que, por primera vez, se han constituido movimientos antisistémicos, políticos, organizados y durables, lo que ha sido una notable creación social, a la cual no obstante y durante mucho tiempo, se le ha dado muy poca atención, además de no haberla analizado tampoco suficientemente. (WALLERSTEIN, 2008, p. 35).
\end{abstract}

El proceso desarrollado por la ACIA -aunque de gran importancia- no llegó a ser tan visible y nombrado para la época como si lo fueron la promulgación de la nueva Constitución Política de Colombia en el año de $1991^{7}$ y la posterior sanción de la Ley 70 en 1993. Sin embargo, es importante hacer un recuento previo de algunos hechos sucedidos antes de la formalización de la Carta de 1991 y de la Ley 70 de 1993, que han merecido menor atención y que pueden contener claves importantes para entender el momento actual del proceso que vive el Pacífico sur colombiano.

Para 1990, y como una estrategia que pretendía asumir el momento histórico y coyuntural de la Asamblea Nacional Constituyente, se celebró en la ciudad de Cali el Encuentro Preconstituyente de Comunidades Negras, liderado por Carlos Rosero, Carlos Ramos (asesinado en 1992) y Gabino Hernández, perteneciente al Palenque de San Basilio. En él, participaron personas y organizaciones de diversa índole (organizaciones de base, partidos políticos tradicionales, organizaciones eclesiales de base, ONG's, etc.) que reclamaban como punto común, un trabajo en la reivindicación de los derechos de estas comunidades. Como fruto de este espacio, surge la Coordinadora Nacional de Comunidades Negras ( $\mathrm{CNCN})$. Sin embargo, "las profundas diferencias, divisiones y enfrentamientos entre los diversos sectores que la integraban y que representaban perspectivas campesinistas, urbanas, populares, étnicas, político tradicionales y de izquierdas, hicieron que la CNCN tuviera una vida limitada". (ESCOBAR, 1999, p. 173).

Una de las tareas fundamentales de este encuentro, era lograr la candidatura de un representante de las comunidades negras a la Asamblea Nacional Constituyente, sin embargo, los orígenes tan disímiles de los representantes y obviamente de sus intereses, no lo permitieron. Así, el sector del Chocó decide apoyar la candidatura del indígena embera Francisco Rojas Birry, y la parte norte del Cauca en unión con un sector de Quibdó, apoyan a Carlos Rosero, éste último no logra ser elegido. Posteriormente,

\footnotetext{
7 "La nueva Constitución de hecho transforma radicalmente el proyecto de nación. Ya no se trata de construir una nación cultural y racialmente homogénea ('todos somos colombianos, todos somos iguales porque todos somos mestizos', donde lo mestizo se codifica culturalmente como blanco); por el contrario, el nuevo proyecto se define como la configuración de una nación pluriétnica y multicultural”. (ESCOBAR, 1999, p. 172-173).
} 
Saturnino Moreno será el delegado de la ACIA ante el equipo asesor de Rojas Birry quien si alcanzó el umbral como constituyente.

Las voces de oposición en contra del reconocimiento de las comunidades negras no se hicieron esperar, los argumentos esgrimidos al respecto, eran entre otros, que estas comunidades "no respondían a la definición académica de grupo étnico, que no tenían lengua, autoridades ni formas de derecho propias, culturalmente habían aceptado elementos que no les eran propios, estaban integrados plenamente como ciudadanos a la vida del país, así, “[...] la inclusión del AT-55 que recoge algunas demandas de las comunidades negras, se logra después de campañas masivas de presión que incluyó toma de edificios, envío de telegramas ${ }^{8}$ desde todo el país y lobby permanente a los constituyentes.”. (ESCOBAR, 1999, p. 174-175).

Ahora bien, la divergente conformación de la $\mathrm{CNCN}$ y las divisiones internas de la organización, fueron algunas de las razones que no permitieron contar con un representante titular en la Asamblea Nacional Constituyente que llevara directamente los intereses y demandas de las comunidades negras, la inclusión del AT-55 además de los esfuerzos referenciados antes, dependió de las gestión de sectores indígenas. Infortunadamente, hasta la fecha, esta situación de 'desarticulación' entre las diferentes organizaciones sociales es constante, y se podría afirmar que es a su vez una de las principales razones para que el proceso no marche al ritmo que debiera. El primer nivel de organización se caracterizó

[...] por la amplia participación de las comunidades en la elaboración de sus derechos, aspiraciones y sueños, reconociendo sus particularidades; este nivel de construcción se hizo desde lo que se llamó internamente "la lógica del río". El segundo nivel, aunque anclado en el río y la vereda, intentó trascender lo rural planteándose las reivindicaciones de la comunidad negra como grupo étnico, más allá aún de lo que pudiese otorgar una ley. A este nivel se buscó rearticular desde las aspiraciones de la gente los conceptos de desarrollo, territorio y las relaciones sociales y políticas de las comunidades negras con el resto de la sociedad colombiana ${ }^{9}$. (ESCOBAR, 1999, p. 177; énfasis agregado).

Para julio de 1992, sesionó en Tumaco, Nariño, la primera Asamblea Nacional de Comunidades Negras, en la cual se procuraron elementos para el desarrollo del AT55. En mayo de 1993 sesionó la segunda Asamblea, donde se aprobó el texto,

\footnotetext{
${ }^{8}$ Como parte de la estrategia comunicativa, y en aras de mostrar a cada uno de los Constituyentes las dinámicas del proceso organizativo, se lanzó la campaña 'telegrama negro'. Con el respaldo de más de 10.000 firmas, se enviaron telegramas a los diferentes Constituyentes desde diferentes lugares de Colombia con la consigna: 'los negros existimos', reclamando su inclusión como grupo étnico en la Constitución que se estaba elaborando. Además de esto, se iniciarían una serie de movilizaciones, entre ellas la toma pacífica de la Catedral y del INCORA en Quibdó y la toma de la Embajada de Haití en Bogotá.

${ }^{9}$ En un momento posterior al desarrollo de la Ley 70, el imaginario político-étnico de la 'comunidad negra' empezará a ser confrontado desde su anclaje a las 'comunidades ribereñas del Pacífico' con las “[...] realidades urbanas, de desplazamiento de poblaciones y pluralidad de experiencias, que demanda re-inventar en aspectos sustantivos el sujeto político de la etnicidad afrocolombiana". (RESTREPO, 2004, p. 276).
} 
previamente concertado entre las organizaciones y el gobierno ${ }^{10}$. La siguiente Asamblea Nacional se realizó en el municipio de Puerto Tejada, departamento del Cauca, en este escenario, se discutió la situación político-organizativa de las comunidades negras. "Con el logro de mecanismos legales de reconocimiento de derechos para la comunidad negra generados por la movilización y construcción social de la protesta [...]". (ESCOBAR, 1999, p. 179).

Uno de los avances más relevantes de este espacio, fue el reconocimiento de la diversidad de grupos de comunidades negras que existen en el país, y en consecuencia, la reflexión sobre cómo cada grupo propende por unos intereses específicos a la vez que encuentra cabida en unos intereses generales. "Como uno de sus aspectos centrales la Asamblea adoptó una declaración de principios político-organizativos formulados a partir de la práctica, visión de vida y aspiraciones de las comunidades, que hacen referencia a la identidad, el territorio, la autonomía y la perspectiva del futuro". (ESCOBAR, 1999, p. 180; énfasis agregado). Dichos principios son:

- La reafirmación del ser (del ser negros)

- Derecho al territorio (un espacio para ser)

- Autonomía (derecho al ejercicio del ser)

- Construcción de una perspectiva propia del futuro

- Somos parte de la lucha que desarrolla el pueblo negro

De esta gran movilización surgirá el Proceso de Comunidades Negras $(\mathrm{PCN})^{11}$ y se empezará a trabajar de una manera contundente por el reconocimiento colectivo del territorio. Revisemos en concordancia, la doble concepción de identidad esbozada por el PCN.

[...] El PCN concibe la identidad de dos modos simultáneos: como anclada en prácticas culturales y saberes consuetudinarios que encarnan ciertas resistencias al capitalismo y a la modernidad, por un lado, y como un proyecto de construcción político cultural siempre cambiante, por el otro. Para el proceso organizativo étnico-cultural, el movimiento debe ser construido con base en demandas amplias por el territorio, identidad y autonomía, y derecho a la propia visión del desarrollo. (ESCOBAR y PEDROSA 1996, p. 356).

\footnotetext{
${ }^{10}$ El AT-55 contemplaba la creación de la Comisión Especial para Comunidades Negras (CECN). "Compuesta por representantes de las comunidades negras, funcionarios de las instituciones gubernamentales involucradas y algunos académicos, en esta CECN se definieron los términos concretos de la etnicidad de comunidad negra y sus derechos territoriales, económicos, políticos y culturales. Después de meses de discusión en la CECN, apuntalado en un intenso trabajo de las organizaciones locales y regionales, fue sancionada la Ley 70 de 1993". (RESTREPO, 2004, p. 274).

${ }^{11}$ A partir de la década de los años 90, empieza a concretarse un proceso de organización en torno al fortalecimiento organizativo y reivindicatorio de las comunidades negras en Colombia, conocido como Proceso de Comunidades Negras PCN, según ESCOBAR (2005: 135), comprende una red de más de 140 organizaciones.
} 
Como el PCN, muchos otros movimientos anclados en una defensa territorial -en- lugar, comenzaron a redefinir la configuración del Pacífico colombiano y han logrado articularse a una red de organizaciones mundiales para llevar su mensaje, sus logros y sus pendientes, es decir, han prefigurado desde la revaloración del lugar ${ }^{12}$, una articulación a dinámicas planetarias que hacen franca oposición a un sistema totalitario que desprecia la vida y adora las cosas. Aún con lo anterior, estaba claro que ni el PCN, ni el resto de las organizaciones sociales y comunitarias, estaban logrando reunir a través de un sentir común, el direccionamiento de los diferentes grupos de gente negra del país.

Desde otro ángulo, veamos ahora, apartes de esta historia en un contexto más local, es decir a la luz de dos procesos de organización/movilización que se gestaron para la época en el municipio de Guapi y que hoy continúan haciendo una interesante apuesta por llevar la lucha de reivindicación y reconocimiento a otro nivel.

\section{Sobre el proceso organizativo en el municipio de Guapi, Pacífico sur colombiano}

A través de nuestro trabajo para socializar y construir del Plan Ambiental en los tres municipios de la costa Pacífica caucana (de sur a norte: Guapi, Timbiquí y López de Micay) entre 2005 y 2007, así como en el trabajo de campo desarrollado entre 2011 y 2012 para esta investigación, tuvimos la oportunidad de conocer y compartir con Orlando Pantoja, quien desde hace más de dos décadas viene desarrollando un proceso serio y comprometido en el fortalecimiento organizativo de las comunidades de su municipio. Su nombre se identifica de inmediato en el Pacífico con la organización que lidera, COCOCAUCA.

La Coordinación de Consejos Comunitarios y Organizaciones de base del Pueblo Negro de la Costa Pacífica del Cauca (COCOCAUCA) nace el 13 de septiembre de 1993, después de casi dos años de trabajos y reflexiones previas, justo al calor de todas las dinámicas que suscitaron después de haber sido sancionada la Constitución Política de 1991. Desde su creación ha propendido por gestar, apoyar y fortalecer la vinculación de las 'comunidades negras' en escenarios locales, regionales, nacionales e internacionales. COCAUCA, como organización de segundo nivel, "cuenta con la mayor agrupación de organizaciones de base de la costa Pacífica del Cauca, conformada por 9 consejos comunitarios (de los 18 que existen en esta región del Cauca) y 3 organizaciones de base (entre ellas JUNPRO ${ }^{13}$ y COPMUJERES ${ }^{14}$ como

\footnotetext{
${ }^{12}$ Tal y como lo ha señalado Escobar, "El lugar - como la cultura local- puede ser considerado 'lo otro' de la globalización, de manera que una discusión del lugar debería ofrecer una perspectiva importante para repensar la globalización y la cuestión de las alternativas al capitalismo y la modernidad". (ESCOBAR, 2000, p. 127). Aún con esto, el autor nos advierte sobre el problema de pensar el 'lugar' y el 'conocimiento local' desde una postura esencialista o mesiánica, "[...] el 'lugar' y el 'conocimiento local' no son panaceas que resolverán los problemas del mundo. El conocimiento local no es 'puro', ni libre de dominación; los lugares pueden tener sus propias formas de opresión y hasta de terror; son históricos y están conectados al mundo a través de relaciones de poder, y de muchas maneras, están determinados por ellas". (ESCOBAR, 2000, p. 129).

${ }^{13}$ Esta organización nace en el municipio de Guapi en el año de 1986 bajo el nombre de JUCODEAGRO (Juventud conquistadora del agro) y a partir de 1991 cambia su nombre a JUNPRO, sus objetivos han girado en torno de resaltar y promover los deberes y derechos étnicos y territoriales de la población afrocolombiana,
} 
las más emblemáticas de esta región)" (COCOCAUCA 2012). Su accionar comprende los municipios de Guapi, Timbiquí y López de Micay.

Destacando su trabajo en la defensa de los derechos étnicos y territoriales de las comunidades afrodescendientes, COCOCAUCA ha trazado una ruta que sobre la reivindicación, propone un análisis en el antes, en el ahora y el después, para esto ha sido fundamental la labor de socialización que alrededor de La Ley 70, del decreto reglamentario 1745 de 1995 y de otros complementos legales, han desarrollado a lo largo y ancho del territorio, así como de los avances y limitaciones que encarna la movilización en sí misma, en un sincero afán por lograr consolidar una línea base enmarcada en el conocimiento general del proceso por parte de toda la comunidad. Esta labor se hace especialmente compleja en la parte rural, donde las condiciones de acceso, el conflicto armado y las limitaciones económicas, entre otras, determinan tiempos y espacios que retardan y cohíben el desarrollo de tal empresa. La conformación y asesoría permanente a los consejos comunitarios, la construcción de Planes de Manejo Ambiental -y sus reglamentos internos-, así como el impulso de cadenas productivas agroecológicas y escuelas de liderazgo, hacen parte del abanico de acciones que promueve esta organización.

Es importante señalar que COCOCAUCA es parte de la "Red de iniciativas y comunidades de paz desde la base" conformada por 25 organizaciones en Colombia (indígenas, afro, campesinas, y de mujeres) que promueven la paz en Colombia patrocinada por SUIPPCOL (Programa Suizo para la Promoción de la Paz en Colombia), de la Mesa Humanitaria del Cauca, de la Mesa Territorial de Garantías (espacio de interlocución con el gobierno frente al tema de derechos humanos), le acompaña el Programa Somos Defensores (plataforma de 4 ONG's nacionales: Asociación Minga, Cinep, Comisión Colombiana de Juristas, y Benposta país de muchachos), e impulsa la escuela de formación con apoyo de ASDI (a través de FOS COLOMBIA)". (COCOCAUCA 2012).

Ante las arremetidas violentas que vive desde hace más de dos décadas el Pacífico, COCOCAUCA ha propendido articular procesos para resistir a la violencia, al desplazamiento forzoso y al despojo de que han venido siendo víctimas las 'comunidades negras' tanto por los grupos armados, legales e ilegales, así como por la cadena de intereses macroeconómicos fijada en esta región, que conviven sutilmente $-\mathrm{y}$ no pocas veces-con los primeros.

Como se señalaba en un aparte anterior, las condiciones de acceso, el conflicto armado en sus diferentes vertientes y las limitaciones de orden económico, confabulan para que el sector rural -que es la inmensa mayoría en el Pacífico colombiano- tenga

su filosofía, propuesta por sus integrantes reza: "para la conservación de la biodiversidad, de nuestras prácticas tradicionales y de nuestros valores culturales". Al igual que la ACIA, JUNPRO va a nacer bajo el auspicio de misiones foráneas de la iglesia católica, y se podría afirmar que es quizá la más antigua de las organizaciones del Pacífico.

${ }^{14}$ La Cooperativa Multiactiva de Mujeres Productivas de Guapi nace en 1992 como resultado de un proceso organizativo de mujeres representado en pequeños grupos productivos y de servicios, todos en busca de integración y solución a los problemas sociales y económicos que enfrentaban las mujeres en su mayoría cabezas de familias. Desde 1993, la Cooperativa hace parte de COCOCAUCA. 
dificultades para articularse a las dinámicas, que si bien se defienden y construyen desde el nivel local, se direccionan con requerimientos muy específicos desde el nivel nacional. En esta medida, hay que resaltar el trabajo que realiza COCOCAUCA. Veamos este ejemplo. Un lugar común para el cumplimiento de la Ley 70 y el decreto reglamentario 1745 habría llegado hasta la conformación de los consejos comunitarios, de acuerdo a todas las disposiciones y requerimientos legales, lo que ya de por sí ha representado una gran empresa por parte de las organizaciones. Sin embargo, después de su creación, las condiciones adversas ya nombradas, incidieron para que en la mayoría de los consejos comunitarios de la costa Pacífica caucana, hasta la reunión anual de las juntas fuera un evento casi imposible. En respuesta a esta situación, COCOCAUCA se ha concentrado en una labor de fortalecimiento a los consejos comunitarios, superando el momento de su creación, y desarrollando un trabajo lento y sostenido en el que ha predominado la cooperación permanente, tal es el caso del Consejo Comunitario de Chanzará, que a pesar de pertenecer a otro municipio (Iscuandé) y a otro departamento (Nariño), encuentra bajo la red tendida por COCOCAUA, un punto de encuentro, de fortalecimiento y de agenda común.

Otra de las más importantes organizaciones devenidas del gran proceso de movilización de la década de los noventa del siglo anterior en el municipio de Guapi, es sin lugar a dudas la Asociación para la defensa del Medio Ambiente y la cultura negra (ASO MANOS NEGRAS), a la cual está indisolublemente asociado el nombre de Yolanda García Loango, lideresa y activista del municipio de Guapi. Fue esta mujer, la que a mi llegada por primera vez a la costa Pacífica caucana, me brindó no sólo su amistad, sino la posibilidad de empezar a dimensionar un proceso que hasta ese momento sólo había conocido, analizado y juzgado a través de fuentes secundarias. Hoy sigue siendo esa mano amable que trata gentilmente de explicarme lo a veces 'inexplicable', entre bosques y ríos, ancestros y tradición.

ASO MANOS NEGRAS creada a finales de 1996. Desde el momento de su concepción y como esfuerzo conjunto de líderes y lideresas, maestros y estudiantes, ha generado un espacio de encuentro para pensar y trabajar en pro de los derechos étnicos de las comunidades negras, educación con pertinencia étnica, cultura y medio ambiente en la costa Pacífica caucana.

Aunque su nacimiento se dio en el municipio de Guapi, ASO MANOS NEGRAS, al igual que COCOCAUCA, tiene influencia en los tres municipios de la costa caucana. Con más diez y seis años de experiencia, ha estado presente de manera ininterrumpida en procesos de fortalecimiento y creación de organizaciones juveniles, asesoría en la implementación de proyectos productivos, creación de consejos comunitarios, además de trabajar permanente y transversalmente desde un enfoque de género y generación.

ASO MANOS NEGRAS ha participado de manera directa en la creación de diez, de los dieciocho consejos comunitarios de la costa Pacífica caucana. Su accionar ha buscado y encontrado un soporte desde las diferentes comunidades, las que a su vez, han calificado sus acciones -no en pocos momentos-, como de gran impacto positivo en los territorios ancestrales. Su citado enfoque transversal en el tema de género y generación, se ha concretado en un gran esfuerzo por llegar a trabajar con mujeres de 
todas las edades, priorizando las zonas rurales del municipio, que a su vez, en muchas ocasiones, son las más lejanas y las de mayor extensión.

Es importante señalar el trabajo en red que se ha fortalecido desde las diferentes organizaciones de base, así como los consejos comunitarios de los tres municipios de la costa Pacífica caucana, claro ejemplo de ello ha sido la campaña "Renacer: desde las entrañas protegiendo el territorio", que se gesta como una iniciativa desde el Consejo Comunitario 'Renacer Negro' de Timbiquí, a él se unieron ASO MANOS NEGRAS y ASOCONSEJOS DE TIMBIQUÍ, en pro de visibilizar la problemática que viven los consejos comunitarios por la presencia de retroexcavadoras que se encuentran en los diferentes ríos para explotación minera. No sólo se reprocha la presencia ilegal e inconsulta de estas maquinarías, sino su estrecha relación con grupos al margen de la ley, lo que agudiza la situación y restringe el sano disfrute del territorio.

De la mano con la Asociación de Consejos Comunitarios de Timbiquí y los Consejos Comunitarios del Río Guajuí, Río Napi y Alto Guapi (Guapi), ASO MANOS NEGRAS presentó el Plan de Etnodesarrollo Regional 2007-2010, bajo el objetivo general de "construir políticas y estrategias que permitan gestionar, mantener y fortalecer el desarrollo de las comunidades afrocolombianas de Guapi, Timbiquí y López de Micay, con el respeto, preservación e integración de nuestras tradiciones e identidad cultural". (Asociación de Consejos Comunitarios de Timbiquí, ASO MANOS NEGRAS y Consejos Comunitarios del Río Guajuí, Río Napi y Alto Napi 2007: 10). Entre sus componentes, se sitúan de manera interdependiente, la educación, el fortalecimiento organizativo, la generación de ingresos y el empleo, la infraestructura y la salud. De igual manera, se presentan como temas transversales: 'Derechos humanos, democracia y paz', 'Género y generación', 'Cultura, Recreación y Deporte' y 'Medio Ambiente'. Para cada momento se planteó un balance de la situación por componente, unas acciones propuestas y sus responsables, así como una serie de indicadores de Etnodesarrollo para su seguimiento y evaluación.

Desde el nivel institucional y personal, tanto COCOCAUCA como ASO MANOS NEGRAS, acompañaron y fortalecieron las líneas planteadas en nuestro Plan Ambiental, así como algunos momentos de implementación, quizá fue esta una de las razones que permitió llevar a la realidad los trazo de una planificación un tanto 'alternativa' que hasta ese momento reposaba sólo en nuestro deseo de tratar de hacer las cosas de otra manera. Ahora bien, la gran amistad que me une con muchos activistas de estas organizaciones y el aprecio profundo a los procesos que desarrollan, no me impide dimensionar que adolecen de la misma patología esgrimida en el ámbito nacional, la desarticulación y la no-comunicación de estas organizaciones, no han permitido que los diferentes procesos alcancen mayor contundencia. En la dinámica de "cada uno por su lado", se pierden muchas veces recursos, y ante todo, la posibilidad de que los impactos de los procesos sean de mayor alcance.

No podría terminar esta sección, sin referirme brevemente, a la Asociación de Organizaciones Populares del Micay (ASOPOMY), con la que he tenido sin lugar a dudas el vínculo más cercano, no sólo por ser la organización con la que desarrollamos nuestro Plan Ambiental, sino porque desde mucho antes de su concreción, forjamos en 
torno a más de dos años de trabajo en la propuesta una muy buena amistad, que además consolidó mi primer acercamiento con el Pacífico.

A diferencia de las dos anteriores, la sede de esta organización de base se encuentra en el municipio de López de Micay, pero al igual que COCOCAUCA y ASO MANOS NEGRAS, su área de influencia comprende los tres municipios de la costa Pacífica caucana. ASOPOMY lucha por la defensa del territorio y por la reivindicación de los derechos étnicos. Además de trabajar proyectos sociales en pro del mejoramiento de la salud, educación y vivienda, ha recogido gran experiencia en torno al desarrollo de toda una estrategia productiva. Al igual que la ACIA y JUNPRO, los orígenes de la organización están sesgados por el clero, específicamente nace a través de un convenio pat misereo con la Prefectura Apostólica de Guapi (sede López de Micay) en 1989 y reactiva su accionar a través de la Comunidad Económica Europea cuando se le adjudica la responsabilidad de manejar el programa de Tiendas Comunitarias. Actualmente, ASOPOMY es la única organización que cuenta con emisora radial comunitaria que está operando con una cobertura de enlace en la parte rural del municipio. Su programación, aparte de ser un puente de ayuda y comunicación permanente para las diferentes comunidades, se ha vinculado activamente a apoyar los procesos de socialización y difusión del momento que actualmente viven las diferentes organizaciones sociales de 'comunidades negras'.

Haciendo una reflexión en torno a lo vivido durante las dos últimas décadas en el Pacífico caucano, David Antonio Torres Riascos, líder, amigo y activista de ASOPOMY decía: "[...] Nuestro proceso organizativo ha tenido una evolución lenta y muchas veces solitaria, si lo comparamos con lo que sucede al interior del país, y aún con la gran problemática que representa para nuestros territorios el conflicto interno, seguimos en procura de construir nuestro espacio de vida desde la 'cultura del agua' y la 'dinámica del río"," 15

\section{Logros, limitaciones y vivencias de la ley 70 de 1993 en el Pacífico sur colombiano}

Tratar de hacer un balance de los procesos vividos en el Pacífico sur colombiano a la luz de la Ley 70 en las dos últimas décadas no es una tarea sencilla, exige entre otras cosas, y a pesar de la muchas veces sobredimensionada concepción de 'homogeneidad' de este territorio, la necesidad de generar estudios particulares que permitan dar cuenta no sólo del avance en términos cuantitativos y de indicadores formales de 'progreso' y 'desarrollo', sino de lecturas que se construyan en torno a las políticas interculturales, a las agendas ambientales compartidas con agencias internacionales, a la incursión del debate sobre el reconocimiento étnico-territorial en un ámbito mundial, a la agudización del conflicto armado, al desplazamiento forzado y a la re-contextualización de las 'comunidades negras' en espacios urbanos, así como al reconocimiento de las limitaciones conceptuales que esgrime la propia ley en términos de inclusión y reconocimiento a todos los grupos de 'comunidades negras' que habitan en el país. Por tal razón, me limitaré a hacer algunas anotaciones muy puntuales.

\footnotetext{
${ }^{15}$ David Antonio Torres. Guapi, 6 de diciembre de 2011.
} 
Quizás uno de los indicadores, que consciente o inconscientemente más se utiliza para evaluar el desarrollo de la Ley 70, es el de la titulación colectiva de tierras $^{16}$. Sin negar el gran logro que esto ha significado en términos de reivindicación y (re)configuración territorial, el análisis debe desplazarse hacia otros lugares que permitan mostrar por ejemplo, el grado de aceptación y de comprensión que suscita el 'consejo comunitario' como máxima autoridad territorial o la posibilidad real de 'disfrute' de estos territorios que hoy tienen adjudicados, al menos teóricamente, las 'comunidades negras'. De igual manera, las cifras de titulación deben ponerse en tensión frente a los contextos y particularidades de cada comunidad.

El proceso de titulación colectiva en el departamento del Cauca empezó relativamente rápido (1998), si se compara con la época en que se otorgaron los primeros títulos del país en el municipio de Riosucio, departamento del Chocó (1996). Esto daba cuenta en primera instancia, que el proceso organizativo estaba sincronizado con las dinámicas de orden nacional y regional y que había un compromiso serio por concretar los desarrollos legales. Sin embargo, al interior del departamento, las dinámicas y tiempos de adjudicación fueron diferentes. Al respecto, podríamos distinguir tres momentos: el primero, comprendido entre 1998 y 2001, cuando el municipio de Guapi completa los títulos para sus cinco consejos comunitarios, el segundo, comprendido entre 2001 y 2002, cuando el municipio de Timbiquí accede a los títulos para sus siete consejos comunitarios, y el tercero y último, comprendido entre 2004 y 2006, cuando el municipio de López de Micay logra acceder a los títulos para sus cinco consejos comunitarios. (Tabla 1).

Tabla 1: Listado cronológico de los títulos colectivos expedidos a favor de las comunidades negras en el departamento del Cauca

\begin{tabular}{l|l|l|l|r|r|c}
\hline Año & Departamento & Municipio & Consejo & \multicolumn{1}{c}{$\begin{array}{c}\text { Total } \\
\text { Familias }\end{array}$} & $\begin{array}{c}\text { Has. } \\
\text { Afrocolombianos } \\
\text { Const. }\end{array}$ & Total Has. \\
\hline 1998 & Cauca & Guapi & $\begin{array}{l}\text { Consejo } \\
\text { Comunitario del } \\
\text { Río Napi }\end{array}$ & 438 & 47.007 .68 & 47.007 .68 \\
\hline 1998 & Cauca & Guapi & $\begin{array}{l}\text { Consejo } \\
\text { Comunitario del } \\
\text { Río San } \\
\text { Francisco }\end{array}$ & 138 & 26.232 .48 & 26.232 .48 \\
\hline 1998 & Cauca & Guapi & $\begin{array}{l}\text { Consejo } \\
\text { Comunitario } \\
\text { Alto Guapi }\end{array}$ & 437 & 103.742 .35 & 103.742 .35 \\
\hline 2001 & Cauca & Guapi & $\begin{array}{l}\text { Consejo } \\
\text { Comunitario del } \\
\text { Río de Guajuí }\end{array}$ & 679 & & \\
\hline
\end{tabular}

16 "La titulación colectiva de las tierras de comunidades negras constituye el proceso más amplio de movilización social organizada de la gente negra colombiana desde la creación de la República de Colombia. Durante una década, desde que fue promulgada la Ley 70, el 27 de agosto de 1993, hasta el año 2003, esta extensa e intensa movilización social cambió la fisonomía de la propiedad sobre el territorio en las tierras bajas del Pacífico colombiano, introduciendo, al igual que en los territorios de resguardos de los pueblos indígenas, una 'revolución' en la territorialidad. (CASTILLO, 2007, p. 307; énfasis agregado). 


\begin{tabular}{|c|c|c|c|c|c|c|}
\hline Año & Departamento & Municipio & Consejo & $\begin{array}{c}\text { Total } \\
\text { Familias }\end{array}$ & $\begin{array}{c}\text { Has. } \\
\begin{array}{c}\text { Afrocolombianos } \\
\text { Const. }\end{array} \\
\end{array}$ & Total Has. \\
\hline 2001 & Cauca & Guapi & $\begin{array}{l}\text { Consejo } \\
\text { Comunitario de } \\
\text { Guapi Abajo }\end{array}$ & 524 & 43.196 .81 & 43.196 .81 \\
\hline 2001 & Cauca & Timbiquí & $\begin{array}{l}\text { Consejo } \\
\text { Comunitario de } \\
\text { Renacer Negro }\end{array}$ & 739 & 71.010 .66 & 71.010 .66 \\
\hline 2001 & Cauca & Timbiquí & $\begin{array}{l}\text { Consejo } \\
\text { Comunitario El } \\
\text { Cuerval }\end{array}$ & 86 & 5.397.39 & 5.397 .39 \\
\hline 2002 & Cauca & Timbiquí & $\begin{array}{l}\text { Consejo } \\
\text { Comunitario de } \\
\text { la Cuenca del } \\
\text { Río San } \\
\text { Bernardo Patía } \\
\text { Norte } \\
\end{array}$ & 196 & 25.652 .39 & 25.652 .39 \\
\hline 2002 & Cauca & Timbiquí & $\begin{array}{l}\text { Consejo } \\
\text { Comunitario } \\
\text { Negros en } \\
\text { Acción } \\
\end{array}$ & 95 & 14.362 .81 & 14.362 .81 \\
\hline 2002 & Cauca & Timbiquí & $\begin{array}{l}\text { Consejo } \\
\text { Comunitario } \\
\text { Negros Unidos } \\
\end{array}$ & 255 & 7.008 .90 & 7.008 .90 \\
\hline 2002 & Cauca & Timbiquí & $\begin{array}{l}\text { Consejo } \\
\text { Comunitario } \\
\text { Parte Alta del } \\
\text { Río Saija } \\
\end{array}$ & 545 & 19.926 .59 & 19.926 .59 \\
\hline 2002 & Cauca & Timbiquí & $\begin{array}{l}\text { Consejo } \\
\text { Comunitario } \\
\text { Parte Baja del } \\
\text { Río Saija }\end{array}$ & 737 & 16.115 .92 & 16.115 .92 \\
\hline 2004 & Cauca & $\begin{array}{l}\text { López de } \\
\text { Micay }\end{array}$ & $\begin{array}{l}\text { Consejo } \\
\text { Comunitario de } \\
\text { San Joc Parte } \\
\text { Alta del Río } \\
\text { Micay } \\
\end{array}$ & 192 & 14.560 .68 & 14.560 .68 \\
\hline 2004 & Cauca & $\begin{array}{l}\text { López de } \\
\text { Micay }\end{array}$ & $\begin{array}{l}\text { Consejo } \\
\text { Comunitario del } \\
\text { Río Chuare }\end{array}$ & 177 & 25.674 .59 & 25.674 .59 \\
\hline 2004 & Cauca & $\begin{array}{l}\text { López de } \\
\text { Micay }\end{array}$ & $\begin{array}{l}\text { Consejo } \\
\text { Comunitario del } \\
\text { Río Sigui }\end{array}$ & 193 & 45.990 .95 & 45.990 .95 \\
\hline 2005 & Cauca & $\begin{array}{ll}\text { López } & \mathrm{de} \\
\text { Micay } & \end{array}$ & $\begin{array}{l}\text { Consejo } \\
\text { Comunitario La } \\
\text { Mamuncia Parte } \\
\text { Media del Río } \\
\text { Micay }\end{array}$ & 866 & 34.252 .08 & 34.252 .08 \\
\hline 2006 & Cauca & $\begin{array}{l}\text { López de } \\
\text { Micay }\end{array}$ & $\begin{array}{l}\text { Consejo } \\
\text { Comunitario } \\
\text { Manglares del } \\
\text { Río Micay }\end{array}$ & 638 & 38.746 .95 & 38.746 .95 \\
\hline \multicolumn{6}{|c|}{ Total Has. } & 574.614 .94 \\
\hline
\end{tabular}

Fuente: Subgerencia de Promoción, Seguimiento y Asuntos Étnicos - Dirección Técnica de Asuntos Étnicos. Actualizada a 2011 por el Observatorio de Territorios Étnicos y filtrada para esta investigación. 

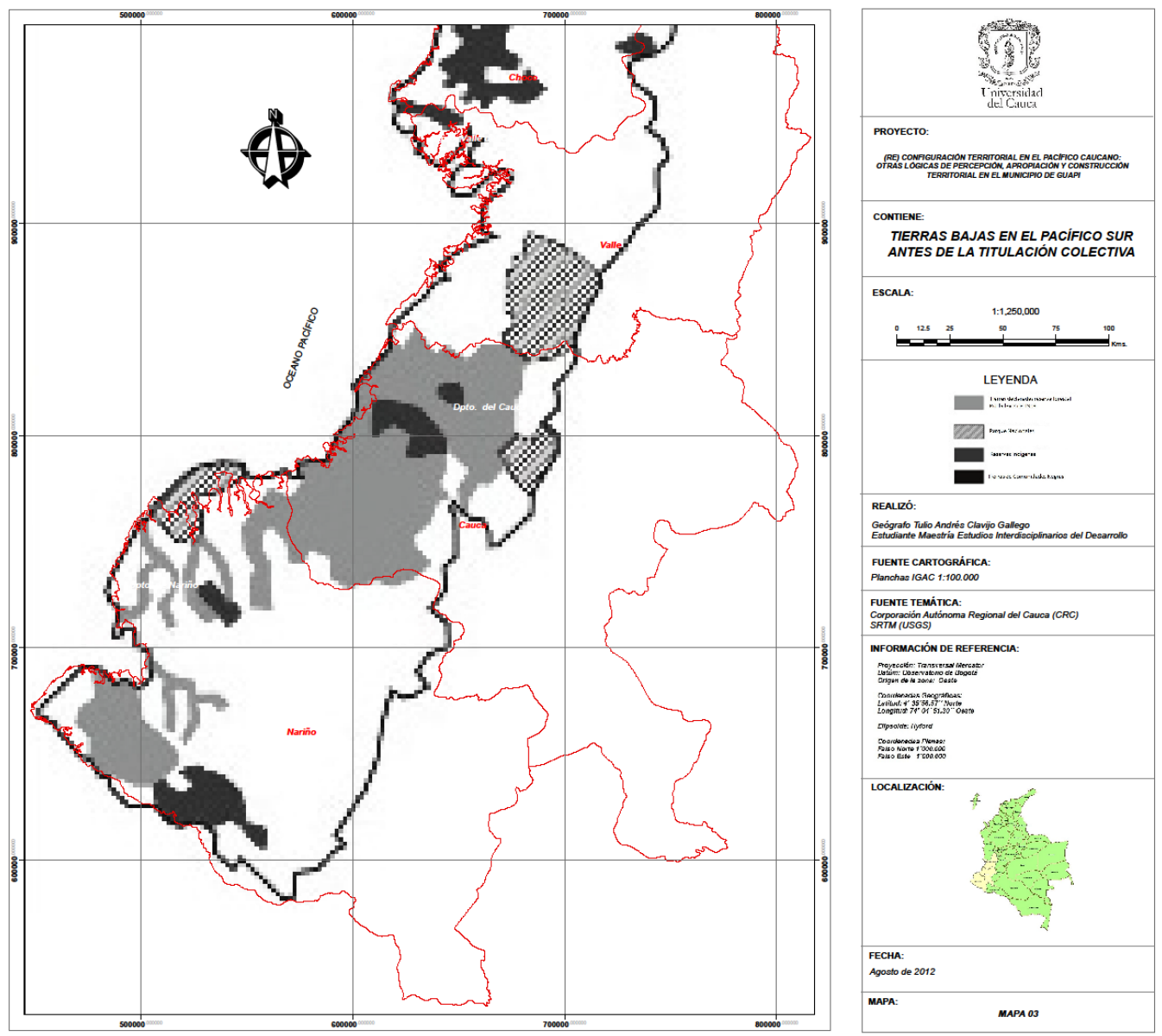

Figura 1: Las tierras bajas del Pacífico sur antes de la titulación colectiva

Sin desconocer que los trámites, la consecución de los documentos y estudios de soporte, ${ }^{17}$ así como las visitas de las comisiones interinstitucionales, dificultaron y dilataron el proceso en todos los departamentos del Andén Pacífico, y que no pocas veces, las solicitudes fueron devueltas en repetidas ocasiones; en el departamento del Cauca, los tiempos de titulación encontrarían una relación directa a las posibilidades de acceso y comunicación con y entre los tres municipios que la conforman. Es decir que de manera adicional a las situaciones anteriormente planteadas, y a los diferentes

\footnotetext{
17 "Para lograr la titulación, la Ley 70 estipula que cada comunidad debía presentar una solicitud al Instituto Colombiano de Reforma Agraria que debía contener información del siguiente tipo: Una descripción física del territorio que se pretende titular, antecedentes etnohistóricos, descripción demográfica del territorio, prácticas tradicionales de producción. Esto indujo de manera indirecta [...] un proceso de titulación y reinvención del territorio que resultó crucial tanto para el proceso de titulación como para el fortalecimiento del discurso étnico territorial del movimiento social". (CASTILLO, 2007, p. 308).
} 
estadios del proceso organizativo que vivía cada municipio, la titulación se dio primero en los lugares en los que el acceso ha sido relativamente más fácil. Veamos, Guapi, que tiene la posibilidad de conexión aérea y fluvial, y que funge como la cabecera más 'desarrollada' fue el primer municipio en completar la titulación para sus consejos comunitarios; Timbiquí, que al igual que el anterior, cuenta con las mismas posibilidades de comunicación y está a menos de una hora en lancha desde Guapi, completó su titulación cuatro años después; pero López de Micay, que es la cabecera municipal más interior de las tres, y que desde hace ya varios años no cuenta con conexión aérea, teniendo como única fuente comunicación el río Micay; fue el que de manera más tardía alcanzó la meta . Así las cosas, López fue el último municipio de la costa Pacífica caucana en completar la titulación, en el año 2006, fecha en la que se otorgó el reconocimiento formal al Consejo Comunitario Manglares del Río Micay.


Figura 2: Las tierras bajas del Pacífico sur después de la titulación colectiva

$\mathrm{Si}$ pretender establecer generalizaciones, las dinámicas diferenciales de titulación en el Pacífico caucano se asemejan también a los diferentes niveles de 
articulación que pudimos observar y vivir en la implementación del Plan Ambiental y en el desarrollo específico de esta investigación. En esta relación, la mayor articulación se logró con los municipios de Guapi y Timbiquí, mientras la más débil fue la establecida con López de Micay. Las posibilidades de acceso y comunicación siempre representaron una barrera a salvar, no sólo para el equipo técnico, sino para las comunidades de diferentes localidades que asistían a los eventos, talleres y encuentros organizados en torno al plan. Siempre fue mucho más fácil generar estos espacios en Guapi y en Timbiquí, que en López de Micay. Éste último municipio ha generado hasta en los propios habitantes de la costa caucana, un imaginario de olvido y de lugar 'recóndito', pude advertir por ejemplo, que para muchos funcionarios de la zona desplazarse hasta allá, ya sea por comisiones cortas o por largas temporadas, es tomado literalmente como un castigo. En alguna ocasión, y antes de abordar la lancha que me llevaría hasta López de Micay, sostenía una charla informal con un habitante de Guapi, al saber de mi destino me dijo: “[...] pa' que va ir allá, allá fue donde el diablo fue a tirar sus botas y más nunca volvió por ellas".

Además de esta relación entre el proceso de titulación y la conectividad, pudimos advertir desde nuestro inicio de labores en campo en el año 2005, cómo después de más de diez años de haber sido sancionada la Ley 70 y de estar titulados casi la totalidad de los consejos comunitarios en los tres municipios, existían no pocos lugares en los que el conocimiento de estas dinámicas era muy bajo, por no decir, inexistente. La figura del 'consejo comunitario' seguía siendo muchas veces intangible, y de otra parte, algunas comunidades y líderes no se sentían incluidas o beneficiadas bajo las nuevas figuras étnicas y territoriales propuestas en la ley e interpretadas por los activistas y organizaciones de los tres municipios. Como lo había comentado en un aparte anterior, hasta la reunión anual de las juntas de los consejos, era una tarea bastante compleja, pues necesitaba garantizar el desplazamiento, hospedaje y logística en general de varios representantes y sus comitivas que venías a su vez de sitios muy lejanos. Estas posibilidades decrecían en relación directa a la distancia, siendo así los consejos comunitarios del municipio de López, los que mayores dificultades encontraban para viabilizar estos encuentros.

Veamos ahora en rasgos generales cuál es el balance de la titulación en un contexto nacional y departamental. De las 5.299.502.41 hectáreas que a 2011 se encuentran tituladas en el país, el departamento del Cauca, posee 574.614.94, es decir, aproximadamente el $10.84 \%$. A nivel del departamento, la mayor titulación se encuentra en el municipio de Guapi (255.915.03 Has) (Tabla 2), algo así como el $44.53 \%$, mientras que Timbiquí y López de Micay se reparten prácticamente a partes iguales el restante departamental, Timbiquí (159.474.66 Has) equivalente al 27.75\%, y López de Micay (159.225.25 Has) con un 27.72\%. 
Tabla 2: Listado cronológico de los títulos colectivos expedidos a favor de las comunidades negras en el municipio de Guapi, departamento del Cauca

\begin{tabular}{|c|c|c|c|c|c|c|}
\hline Año & Departamento & Municipio & Consejo & $\begin{array}{c}\text { Total } \\
\text { Familias }\end{array}$ & $\begin{array}{c}\text { Has. } \\
\begin{array}{c}\text { Afrocolombianos } \\
\text { Const. }\end{array} \\
\end{array}$ & Total Has. \\
\hline 1998 & Cauca & Guapi & $\begin{array}{l}\text { Consejo } \\
\text { Comunitario del } \\
\text { Río Napi }\end{array}$ & 438 & 47.007 .68 & 47.007 .68 \\
\hline 1998 & Cauca & Guapi & $\begin{array}{ll}\text { Consejo } & \\
\text { Comunitario del } \\
\text { Río } & \text { San } \\
\text { Francisco } & \\
\end{array}$ & 138 & 26.232 .48 & 26.232 .48 \\
\hline 1998 & Cauca & Guapi & $\begin{array}{l}\text { Consejo } \\
\text { Comunitario } \\
\text { Alto Guapi }\end{array}$ & 437 & 103.742 .35 & 103.742 .35 \\
\hline 2001 & Cauca & Guapi & $\begin{array}{l}\text { Consejo } \\
\text { Comunitario del } \\
\text { Río de Guajuí }\end{array}$ & 679 & 35.735 .71 & 35.735 .71 \\
\hline 2001 & Cauca & Guapi & $\begin{array}{l}\text { Consejo } \\
\text { Comunitario de } \\
\text { Guapi Abajo }\end{array}$ & 524 & 43.196 .81 & 43.196 .81 \\
\hline \multicolumn{6}{|c|}{ Total Has. } & 255.915 .03 \\
\hline
\end{tabular}

Fuente: Subgerencia de Promoción, Seguimiento y Asuntos Étnicos - Dirección Técnica de Asuntos Étnicos. Actualizada a 2011 por el Observatorio de Territorios Étnicos y filtrada para esta investigación.

Si bien estas cifras demuestran que se ha avanzado en formas de acceso y control territorial, es igualmente cierto que existen grandes limitaciones en cuanto al "[...] uso, manejo, movilidad e incluso formalización del derecho a la propiedad colectiva". (HERRERA, 2012, p. 3). Al mismo tiempo que se estaba llevando a cabo la entrega de los primeros títulos colectivos en el país, las arremetidas del conflicto armado se desplazaban con mayor contundencia hacia estos territorios, generando desplazamiento o confinando, restringiendo usos y formas de vida.

Adicionalmente, al menos hasta 2011, eran más de veinte las solicitudes de titulación colectiva que habían sido rechazadas y casi un igual número las que se encuentran en estudio, con gran posibilidad de rechazo. En la mayoría de estos casos la razón de negación descansaba en el argumento de que los predios que estaban siendo solicitados aparecían registrados como 'propiedad privada' de manera parcial o total. Pero más allá de la veracidad de este argumento, la negativa estaba amparada tácitamente en que las comunidades solicitantes no estaban asentadas en la cuenca del Pacífico colombiano. A pesar de que la ley abrió el espectro y hablo de otras 'comunidades negras' que pudieran ser similares a las descritas, es decir, que fueran ribereñas, demostraran antigüedad de asentamiento y sostuvieran prácticas de manejo tradicional como beneficiaras de esta ley, pareciera que ésta opera sólo en el Pacífico, 
lo que asociaría que 'comunidades negras' en el país, sólo son legalmente, las que habitan estos territorios. ${ }^{18}$

Así, aunque la Ley 70 se trataba principalmente de las comunidades negras en la región de la costa Pacífica, los artículos que se referían a los afrocolombianos de fuera de esa región abonaron el terreno para que 'aparecieran' comunidades negras en donde se había pensado que era imposible. (WADE, 2010, p. 481). Sin embargo, no han sido pocas las dificultades que las 'comunidades negras' ubicadas en otras zonas del país han tenido que superar en sus diferentes procesos de reclamos territoriales, en un primer momento, encontrarse ubicadas dentro de territorios andinos, ha generado dificultades para su comprensión y asimilación desde el ámbito político y académico, justamente, porque desde el imaginario tradicional, estas comunidades no encajan con la concepción y regionalización del territorio nacional, situación que es complementada además con la reciente 'etnización' de la gente negra, propiciando un inexorable vínculo con el Pacífico. En esta materia, el profesor Axel Rojas (2004a; 2004b) ha presentado un interesante estudio basado en la presencia de 'comunidades negras' en un enclave andino del departamento del Cauca.

En otro momento, y aunque pudiera pensarse que su ubicación costera podría facilitar un poco más las cosas, las 'comunidades negras' asentadas en la costa caribe, han tenido que sobrellevar un largo y agotador proceso en pro de la consecución de sus derechos territoriales. El ejemplo más diciente al respecto -quizás por su coyuntura estratégica con la Cumbre de las Américas celebrada en Cartagena en abril de 2012fue la entrega de territorios colectivos a las 'comunidades negras' de San Basilio del Palenque $^{19}$ y La Boquilla por parte del presidente de los Estados Unidos, Barack Obama. El Consejo Comunitario de Makankamaná, en San Basilio del Palenque recibió un título por 3.500 hectáreas, mientras que el Consejo Comunitario de La Boquilla, ubicado entre la Ciénaga de la Virgen y la cabecera municipal de Cartagena, recibió un título por cerca de 40 hectáreas. Si bien, estos procesos están amparados bajo los principios consignados en la Ley 70 de 1993, cabe resaltar que estos dos títulos constituyen su primera aplicación formal en el Caribe colombiano. Tanto Sebastián

\footnotetext{
${ }^{18}$ La Ley 70 de 1993 reconoce a los grupos de 'comunidades negras' como el '[...]conjunto de familias de ascendencia afrocolombiana que poseen una cultura propia, comparten una historia y tienen sus propios usos y costumbres dentro de la relación como poblado, que revelan y conservan una conciencia de identidad que las distingue de otros grupos étnicos. (HOFFMANN, 2007, p. 26; énfasis en el original). No obstantes los logros obtenidos a través del desarrollo de la enunciada ley, también hay en su haber grandes pendientes, el más inmediato quizá, “[...] ha sido la dificultad de imaginar unos sujetos políticos y de derechos étnicos por fuera del Pacífico y de las imágenes acuñadas de 'comunidades negras' como unas radicales alteridades culturales de occidente y de la modernidad”. (RESTREPO, 2012, p. 213).

19 San Basilio del Palenque es reconocido como el primer pueblo libre de América, "[...] ubicado aproximadamente a 70 kilómetros de Cartagena, fue fundado en 1713 mediante una 'entente cordiale', un pacto de concesiones mutuas que firmaron los habitantes de San Basilio con el obispo de Cartagena Fray Antonio María Casiani después de varios intentos de las tropas coloniales españolas por destruirlo y a su población rebelde. [...] El palenque de San Basilio se ha mantenido como uno de los símbolos más visibles de la resistencia negra en toda América, y sus habitantes han sido llamados 'el primer pueblo libre de América'. [...] Uno de los fenómenos socioculturales más estudiados en San Basilio es la lengua creole, desarrollada en suelo americano, que debe sus influencias al español así como a diferentes lenguas africanas". (OSLENDER, 2008, p. 178; énfasis en el original). En 2005, San Basilio del Palenque fue declarado por la UNESCO como Obra Maestra del Patrimonio Oral e Inmaterial de la Humanidad.
} 
Salgado, representante del Consejo Comunitario Makankamaná, como Benjamín Luna Lozano, representante del Consejo Comunitario de La Boquilla, reconocen que este es el primer logro después de casi una década de trabajo arduo y sostenido, en el que han tenido que asumir más de un desplante por parte del Estado.

Por su parte, Juan Carlos Betancourt, del Observatorio de Territorios Étnicos de la Universidad Javeriana, señala en artículo publicado por Alfredo Molano ${ }^{20}$ en el periódico El Espectador, que son muchos los peligros a los que se ven enfrentados estas comunidades, el drástico incremento de la actividad ganadera y de los monocultivos de caña, arroz y algodón, así como los proyectos madereros y de minería. Si a esto se le suma la creciente urbanización encarnada en proyectos turísticos, estos territorios colectivos se encuentran prácticamente cercados por una serie de dinámicas y prácticas que ven en este tipo de reconocimiento, como una 'piedra en el zapato' para el desarrollo de sus actividades. Hasta dónde entonces la consecución de estos títulos representa un triunfo real para las comunidades Palenqueras del Caribe colombiano o hasta donde dicho reconocimiento se inscribe hábilmente en la política multicultural de estado, que funcionaliza la diferencia cultural en pro apaciguar momentáneamente las voces de protesta y de garantizar un tránsito libre y seguro hacia los nuevos pactos económicos internacionales. Esto estaría inmerso en una etapa más avanzada de la confluencia señalada por Wade (2004) entre el multiculturalismo, la restructuración de las economías neoliberales y el ambientalismo vías fase ecológica del capital. En la que además, las comunidades son embestidas como protectoras y guardianas de los territorios.

Según el sentir y pensar de varias de los organizaciones que hacen presencia en el municipio de Guapi, los logros más grandes que se han tenido en la región después de sancionada la Ley 70 son: a) la previa inclusión del AT-55 en la Constitución Política de 1991 y su posterior desarrollo a través de la Ley 70 de 1993, b) la reglamentación del capítulo III de la ley, que devino en la titulación colectiva y en la conformación de los consejos comunitarios, c) la conformación de organizaciones de base con articulación en el nivel municipal, regional y nacional, d) la documentación de experiencias sobre Etnodesarrollo, que se materializó en publicaciones y documentales, e) la instauración de la catedra de estudios afrocolombianos, así como la mayor presencia de instituciones educativas, y f) la mayor articulación con procesos organizativos en el ámbito internacional. De igual manera, los pendientes se circunscriben a aspectos como: a) el desconocimiento de la Ley 70 y del proceso organizativo en muchas localidades de los tres municipios, b) se debe continuar con el proceso de reglamentación de la ley, lo que tocaría aspectos tan álgidos como la minería y las prácticas ambientales, c) lograr un mejor aprovechamiento de los espacios de representatividad ganados a nivel nacional y regional, ya que se están convirtiendo en lugares de burocracia y de plataforma política para el cumplimiento de intereses individuales, y d) propender por una mayor y más activa participación del gobierno nacional, en aras de garantizar el disfrute de los territorios frente a la realidad del conflicto armado, el desplazamiento y los cultivos de uso ilícito, que han venido

\footnotetext{
20 "La recompensa a una lucha", por Alfredo Molano Jimeno. Este artículo fue publicado por el periódico El Espectador el domingo 15 de abril de 2012.
} 
restringiendo y confinando las posibilidades de ir y venir, de ser y de estar en los territorios.

\section{Conclusión provisional}

Partiendo de que el proceso de organización y movilización previo y posterior a la promulgación de la Ley 70 de 1993 se vivió de diferentes maneras en el Pacífico colombiano, se hace necesario situar los análisis con elementos, que si bien asientan por develar y comprender los tejidos que inexorablemente vinculan al litoral como territorio-región, permitan también establecer lecturas lugarizadas que den cuenta de los diferentes acentos, concepciones, emergencias y difusiones de las experiencias vividas y por vivir.

A la par de hacer una revisión del proceso de organización y movilización de la gente negra en un contexto nacional y regional, se ha querido presentar una suerte de primera genealogía sobre cómo operaron estas dinámicas en la costa Pacífica caucana. A pesar de que la lectura sigue siendo parcial y limitada, es importante señalar que así como hubo una gran eclosión en la creación de organizaciones al tenor de las disposiciones constitucionales en el ámbito nacional y regional, muchas de ellas no alcanzaron a tener un desarrollo de mayor aliento desapareciendo poco tiempo después. En esta medida, el trabajo de organizaciones como COCOCAUCA y ASOMANONEGRAS adquieren una dimensión especial, pues no sólo encuentran su origen en la coyuntura señalada, sino que a través del tiempo y sorteando todo tipo de dificultades, se han mantenido firmes tanto en sus agendas políticas como en su trabajo decidido y participativo con las diferentes comunidades, superando no en pocos casos las barreras que establecen las concepciones político administrativas tradicionales y el proyecto de un país que infortunadamente se sigue construyendo de espaldas a muchos de sus territorios y de sus gentes.

Finalmente, en aras de fortalecer el proceso de titulación colectiva de una forma incluyente, debe ser una empresa firme el avanzar hacia un marco de aplicación más amplio de la Ley 70 , que permita que otros grupos de gente negra en todo el país puedan acceder a los beneficios de ser reconocidos bajo sus prácticas ancestrales en territorios colectivos. Si bien ya se han dado los primeros pasos al respecto, la titulación por fuera de la cuenca del pacífico es aún hoy incipiente.

\section{Referencias}

ASOCIACIÓN DE CONSEJOS COMUNITARIOS DE TIMBIQUÍ, ASO MANOS NEGRAS y CONSEJOS COMUNITARIOS DEL RÍO GUAJUÍ, RÍO NAPI Y ALTO NAPI. Plan de Etnodesarrollo Regional 2007-2010 Costa Pacífica Caucana. ASO MANOS NEGRAS. 2007

ASOPOMY. Plan Ambiental de las Comunidades Negras de la Costa Pacífica Caucana, con Participación Comunitaria y Diálogo de Saberes. Documento final de 
investigación presentado por la Asociación de Organizaciones Populares del Micay ASOPOMY ante la Corporación Autónoma Regional del Cauca CRC. 2007.

CASTILLO, Luis Carlos. Etnicidad y nación: el desafío de la diversidad en Colombia. Universidad del Valle, Cali. 2007.

COCOCAUCA. Información disponible en: www.cococauca.org. Consultada 12/06/2012.

ESCOBAR, Arturo. Territorios de diferencia. Lugar, movimientos, vida, redes. Envión Editores, Popayán. 2010.

ESCOBAR, Arturo. "El lugar de la naturaleza y la naturaleza del lugar: globalización o posdesarrollo"; En Andreu Viola (Comp). Antropología del desarrollo. Teorías y estudios etnográficos en América Latina. pp 113-143, Barcelona, Editores Paidós. 2010.

ESCOBAR, Arturo. Más allá del tercer mundo. Globalización y Diferencia. Instituto Colombiano de Antropología Icanh. Santafé de Bogotá. 2005.

ESCOBAR, Arturo. El final del salvaje. Naturaleza, cultura y política en la antropología contemporánea. CEREC, ICAN, Bogotá. 1999.

ESCOBAR, Arturo y PEDROSA, Álvaro (eds.). Pacífico: ¿Desarrollo o diversidad? Estado, capital y movimientos sociales en el Pacífico colombiano. Bogotá: CEREC. 1996

FOUCAULT, Michel. Historia de la sexualidad. 1. La voluntad del saber. Siglo xxi Editores, México. [1977] 2011

HERRERA, Johana. Cifras, lugares y temporalidades para entender el giro territorial. En: Serie, Memoria y Territorio. Observatorio de Territorios Étnicos. Universidad Javeriana, Bogotá (en prensa). 2012.

HOFFMANN, Odile. Comunidades negras en el Pacífico colombiano. Innovaciones y dinámicas étnicas. Ediciones Abya-Yala, Quito, Ecuador. 2007.

OSLENDER, Ulrich. Comunidades negras y espacio en el pacífico colombiano: hacia un giro geográfico en el estudio de los movimientos sociales. Instituto Colombiano de Antropología ICANH, Bogotá-Colombia. 2008.

RESTREPO, Eduardo. Intervenciones en teoría cultural. Editorial Universidad del Cauca, Popayán. 2012 
RESTREPO, Eduardo. "Multiculturalismo, gubernamentalidad, resistencia”. En: Oscar Almario y Miguel Ruiz (eds.), El giro hermenéutico de las ciencias sociales y humanas. pp. 35-48. Universidad Nacional, Medellín. 2008.

RESTREPO, Eduardo. Políticas de la teoría y dilemas en los estudios de las colombias negras. Editorial Universidad del Cauca, Colección Políticas de la alteridad, Colombia, Popayán. 2005.

RESTREPO, Eduardo. "Biopolítica y alteridad: dilemas de la etnización de las colombias negras". En: Eduardo Restrepo y Axel Rojas (eds.), Conflicto e invisibilidad. Retos de los estudios de la gente negra en Colombia. pp. 271-300. Popayán: Editorial Universidad del Cauca. 2004.

ROJAS, Axel (coordinador). "Subalternos entre los subalternos: presencia e invisibilidad de la población negra en los imaginarios teóricos y sociales". Eduardo Restrepo y Axel Rojas (eds.), Conflicto e invisibilidad. Retos de los estudios de la gente negra en Colombia. pp. 155-170. Popayán: Editorial Universidad del Cauca. 2004a.

ROJAS, Axel. Si no fuera por los Quince Negros. Memoria colectiva de la gente de Tierradentro. Editorial Universidad del Cauca, Popayán. 2004b

SERJE DE LA OSSA, Margarita Rosa. El revés de la Nación: Territorios salvajes, fronteras y tierras de nadie. Universidad de los Andes, Facultad de Ciencias Sociales, Departamento de Antropología, CESO, Ediciones Uniandes, Bogotá, Colombia. [2005] 2011.

WADE, Peter. "Liberalismo, raza y ciudadanía en Latinoamérica”. En: Mosquera Rosero-Labbé, Claudia, Agustín Laó-Montes y César Rodríguez Garavito (Editores y coautores), Debates sobre ciudadanía y políticas raciales en las Américas Negras. pp. 467-486 Universidad Nacional de Colombia, Bogotá. 2010.

WADE, Peter. "Los guardianes del poder: biodiversidad y multiculturalidad en Colombia". En: Eduardo Restrepo y Axel Rojas (eds.), Conflicto e invisibilidad. Retos de los estudios de la gente negra en Colombia. pp. 249-269. Popayán: Editorial Universidad del Cauca, Popayán. 2004.

WALLERSTEIN, Immanuel. Historia y dilema de los movimientos antisitémicos. Ediciones desde abajo, Bogotá, D.C, Colombia. 2008. 
Tulio Andrés Clavijo Gallego

Profesor e investigador del Departamento de Geografía de la Universidad del Cauca, Colômbia.

Geógrafo, Magister en Estudios Interdisciplinarios del Desarrollo. Candidato a Doctor en Antropología por la Universidad del Cauca.

Calle 4 No. 3-56. Popayán - Cauca - Colombia

E-mail: taclavijo@unicauca.edu.co

Recebido para publicação em julho de 2014 Aprovado para publicação em março de 2015 